\title{
Overgeneralized autobiographcial memory of depressed Korean elderly
}

\author{
Jaehee Kim, Sungwon Choi ${ }^{\dagger}$ \\ Duksung Women's Univiersity
}

\section{INTRODUTION}

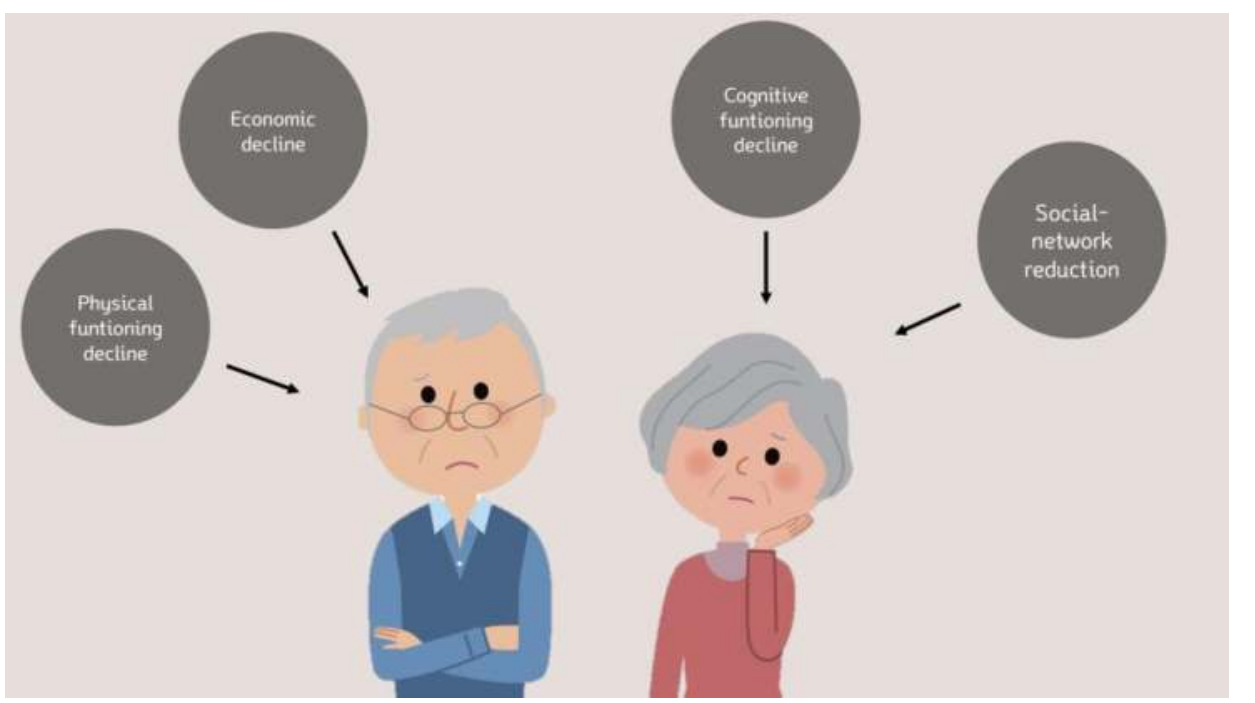

In elderly, memory problems occur due to various factors such as aging and cognitive functioning decline. One of them is depression. Older people with depression than healthy people had problems when they recall their autobiographical memory. Previous studies have found that depressed people have difficulty recalling certain memories when they recall their autobiographical memories.

- Our research has used a free-release method to minimize such control. Accordingly, in a semi-structured interview interviewer, our research would like to compare these differences in group comparisons between depressed and non-depressive older people in interview situations where there is no free reflection and no more than a certain amount of control is imposed.

\section{METHOD}

Participants
Participants targeted elderly people living in Wonju, Gangwon
Province, South Korea.
Thelusion criteria
- Grouping
Depressive Group is GDS score $\geq 10$
Non-depressive Group is Depressive Group Pair

\section{TABLE1. DEMOGRAPHIC}

\begin{tabular}{|ccc|}
\hline Characteristics & N, Mean & SD, \% \\
\hline Sex(Female) & 12 & 60 \\
Age & 69.9 & 3.94 \\
Education & 6.95 & 3.87 \\
MMSE & 26.10 & 3.07 \\
GDS & 8.05 & 4.86
\end{tabular}

\begin{abstract}
Procedure
List the events that may be experienced in life in a semistructured interview, and ask the interviewer to recall specific events, including time and place, by selecting the three events and reminiscing them in the order of the most important events.

Interrater Reliability measurements were rated by two master clinical psychology students. Coefficients were .96
\end{abstract}

\section{Analyze}

Analysis used SPSS ver.21 and performed one-way ANOVA Additionally, After we set up MMSE score into covariance we has analyzed data.

\section{RESULT}

- There are participant's demographic information in table1. We founded specific memory different between depression group and non-depression group. When they recalled autobiographical memory, Depressive group recalled overgeneralized memory more than non-depressive group.

\section{CONCLUSION}

- Our research made up semi-structured The Autobiographical Memory Interview, also the results were the same as previous studies.

If you have any questions,

Use the QR corde.

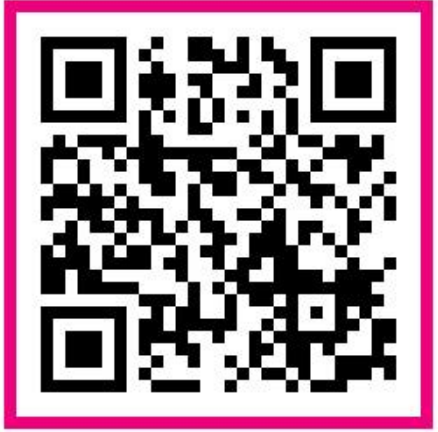

TABLE2. one-way ANOVA

$(\mathrm{N}=20)$

\begin{tabular}{cccccc} 
& $\begin{array}{c}\text { Sum of } \\
\text { Square } \\
\mathrm{s}\end{array}$ & df & $\begin{array}{c}\text { Mean } \\
\text { Square }\end{array}$ & $\mathrm{F}$ & Sig. \\
\hline Group & 49.143 & 1 & 49.143 & 18.793 & .000 \\
MMSE & .070 & 1 & .070 & .027 & .872 \\
Score & 070 & & & & \\
Total & $\begin{array}{c}202.25 \\
0\end{array}$ & 20 & & & \\
\hline
\end{tabular}

